\title{
Ball-Tipped Periodontal Probe
}

National Cancer Institute

\section{Source}

National Cancer Institute. Ball-Tipped Periodontal Probe. NCI Thesaurus. Code C114643.

A periodontal probe with a $0.5 \mathrm{~mm}$ diameter ball tip and a color-coded band extending

$3.5 \mathrm{~mm}$ to $5.5 \mathrm{~mm}$ from the tip. It is typically used to determine sulcus depth for periodontal screening and recording. 